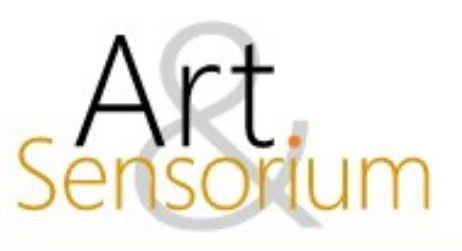

\title{
DUREGRAPH: UMA ABORDAGEM METODOLÓGICA PARA INVESTIGAÇÃO DA DURAÇÃO ATRAVÉS DA PRÁTICA FOTOGRÁFICA
}

\author{
https://doi.org/10.33871/23580437.2021.8.1.203-214
}

\author{
David Van Vliet ${ }^{1}$ \\ Marcos Mortensen Steagall ${ }^{2}$
}

\begin{abstract}
RESUMO: Este artigo considera o arcabouço metodológico que foi desenhado para a pesquisa de mestrado em Design orientada pela prática e nominada Duregraph: Uma abordagem metodológica da duração na imagem fotográfica. Atualmente existe uma grande valorização das metodologias de pesquisa em arte e design capazes de produzir investigações que informem a prática e onde a prática, o conhecimento e a escrita da contextualização dessa epistemologia. Duregraph é um neologismo desenvolvido para expressar considerações artísticas realizadas através da imagem fotográfica para a investigação de uma realidade temporal que se desprende de quantificações matemáticas para questionar a duração e formas de representação que investigam a inversão das relações de poder entre imagem e sua audiência. O objetivo do artigo e de trazer a luz do escrutínio o pensamento utilizado na construção da pesquisa que teve na fotografia em estúdio como forma de questionamento através da prática.
\end{abstract}

PALAVRAS-CHAVE: Fotografia; Pós-Fotográfico; Pesquisa orientada pela prática; Duração; Metodologia.

\section{DUREGRAPH: UN ENFOQUE METODOLÓGICO PARA INVESTIGAR LA DURACIÓN A TRAVÉS DE LA PRÁCTICA FOTOGRÁFICA}

RESUMEN: Este artículo considera el marco metodológico que se diseñó para la investigación del máster en Diseño guiado por la práctica y denominado Duregraph: Una aproximación metodológica a la duración en la imagen fotográfica. Actualmente, existe una gran apreciación de las metodologías de investigación en arte y diseño capaces de producir investigaciones que informen la práctica y

\footnotetext{
${ }^{1}$ Professor no curso de Comunicação e Design na Universidade de Tecnologia de Auckland (AUT), onde também concluiu o Mestrado em Design com o projeto intitulado Durograph. Este estudo, conduzido pela prática, explorou como o tempo vivido pode ser articulado por meio de imagens fotográficas manipuladas. Sua pesquisa está relacionada ao potencial das tecnologias emergentes e como isso pode mudar a forma como tratamos as imagens na fotografia e no design. ORCID 0000-0003-1480-3018.

${ }^{2}$ Marcos Mortensen Steagall é professor do Curso e Design da Auckland University of Technology (AUT). Possui ampla experiência no conhecimento, desenvolvimento e implementação de currículos educacionais, liderando os esforços de equipes acadêmicas. Marcos tem mestrado (2000) e doutorado (2006) em Comunicação e Semiótica adquiridos na Pontifícia Universidade Católica de São Paulo (PUC-SP), Brasil, e Ph.D. em Arte e Design concedido pela Auckland University of Technology (AUT) em 2019. Seus interesses de pesquisa estão ligados a semiótica visual; metodologias de pesquisa orientadas para a prática em Arte, Design e Tecnologia; Produção de imagens baseadas em lentes e epistemologias indígenas. ORCID 0000-0003-2108-4445
} 
donde la práctica y el conocimiento y la escritura contextualicen esta epistemología. Duregraph es un neologismo desarrollado para expresar consideraciones artísticas realizadas a través de la imagen fotográfica para la investigación de una realidad temporal que se desprende de las cuantificaciones matemáticas para cuestionar la duración y las formas de representación que investigan la inversión de las relaciones de poder entre la imagen y su audiencia. El objetivo del artículo es traer la luz del escrutinio al pensamiento utilizado en la construcción de la investigación que tuvo en fotografía de estudio como una forma de cuestionamiento a través de la práctica.

PALABRAS CLAVE: Fotografía; Post-fotográfico; Investigación orientada a la práctica; Duración; Metodología.

\title{
DUREGRAPH: A METHODOLOGICAL APPROACH TO INVESTIGATE DURATION THROUGH PHOTOGRAPHIC PRACTICE
}

\begin{abstract}
This article considers the methodological framework that was designed for a practiceled research project for a Master's degree in Design named Duregraph: A methodological approach to duration in the photographic image. Currently, there is a great appreciation of research methodologies in art and design capable of producing investigations that inform practice, where practice, knowledge and writing contextualize this epistemology. Duregraph is a neologism developed to express artistic considerations made through the photographic image for the investigation of a temporal reality that is detached from mathematical quantifications. These images question duration and forms of representation to investigate the inversion of the power relations between image and its audience. The purpose of the article is to bring the light of scrutiny to the thinking used in the construction of the research as a way of questioning through practice.
\end{abstract}

KEYWORDS: Photography; Post-Photographic; Practice-oriented research; Duration; Methodology.

\section{INTRODUÇÃO}

Uma pesquisa orientada para a prática consiste em programas de pós-graduação baseados em design, tanto no nível de mestrado quanto no de doutorado, que contêm a prática como um componente integrado de estudo. Ela é uma parte familiar da pesquisa em arte e design no Reino Unido, Escandinávia e Australásia, enquanto há uma difusão dela em países como Estados Unidos, Canadá e Europa. De acordo com MORTENSEN STEAGALL e INGS (2018, p.395) "A pesquisa conduzida para prática permite aos praticantes de arte e design abordagens para descobrir, aplicar e comunicar conhecimentos originais que têm implicações diretas para sua prática".

Este artigo descreve a metodologia projetada para uma pesquisa conduzida pela prática em que o foco principal do profissional é "avançar o conhecimento sobre a prática ou avançar o conhecimento dentro da prática" (CANDY, 2006, p. 1). O artigo discute o desenho de pesquisa do projeto ao mesmo tempo em que localiza o estudo paradigmaticamente, discute a abordagem metodológica e, a seguir, desdobra os métodos empregados na investigação. Completa-se com uma crítica à metodologia e a apresentação de duas imagens com considerações. 


\section{PESQUISA ARTÍSTICA E METODOLOGIA}

A investigação artística apresentada neste artigo parte de um paradigma conduzido pela prática e é útil considerar a metodologia empregada em sua explicação. GUBA e LINCOLN (1994, p. 108) sugerem que a metodologia em uma pesquisa pergunta: "Como o inquiridor pode descobrir tudo o que acredita que pode ser conhecido?". Na investigação artística, essas questões são investigadas por meio da prática, com reflexão crítica sobre essa prática e refinamento iterativo dos resultados emergentes. Em termos metodológicos, este projeto constitui uma investigação conduzida para a prática, dirigida à descoberta através da prática artística.

MOUSTAKAS (1990, p. 9) define uma investigação heurística como "um processo de busca interna por meio do qual se descobrem a natureza e o significado da experiência e se desenvolvem métodos e procedimentos para investigação e análise posteriores". A investigação heurística permite que um pesquisador:

[...] encontre conhecimento, padrões ou um resultado desejado por meio de questionamentos informais e suposições, em vez da aplicação de fórmulas préestabelecidas. Como forma de investigação, utiliza níveis sofisticados de subjetividade informada e conhecimento tácito para resolver problemas criativos complexos. (INGS, 2011, p. 73).

Segundo VENTLING (2018, p. 127), a adaptabilidade dos processos de investigação heurística, combinada com sua ênfase em um ponto de vista pessoal subjetivo, torna-a "atraente e relevante para o campo da pesquisa artística". No entanto, este estudo abandonou a ênfase na investigação heurística na interioridade quando buscou feedback externo sobre os desenvolvimentos iterativos do trabalho. Sela-Smith, em sua crítica da prática de pesquisa heurística de Moustakas (2002, p. 71) adverte contra a abertura de tais investigações à crítica externa porque, ela sugere, isso pode levar a uma "confusão de ... diferentes perspectivas e diferentes significados, [que] podem desorientar totalmente o pesquisador".

Dentro da investigação heurística, foi útil o conceito de prática reflexiva de SCHÖN (2016). É um processo no qual está sendo criado, questionando tanto a eficácia do trabalho em relação à pesquisa quanto a adequação da forma, pela qual a pesquisa se insere.

\section{METODOLOGIA}

Este estudo empregou métodos distintos, mas inter-relacionados, que se enquadram em quatro fases. A fase 1 tratava das atividades de concepção e planejamento. A fase 2 envolveu a execução do plano por meio de filmagens e experimentação em estúdio. A fase 3 envolveu o processamento dos dados capturados. A fase final envolveu a busca de feedback estratégico que pudesse impactar nos refinamentos dos projetos.

\section{Estágio 1: Planejamento}

\section{Desenho}

PALLASMAA (2017, p. 104) argumenta que esboçar pode ser um processo de pensamento, no qual: 
A mão capta a fisicalidade e materialidade do pensamento e o transforma numa imagem concreta. Nos árduos processos de desenho, a mão passa amiúde a liderar a sondagem de uma visão ou de um vago pressentimento, que ela, a mão, eventualmente transforma num esboço, materializando, assim, a ideia.

O desenho é um método usado para visualizar e planejar iterações de pensamento. Este processo envolveu a construção de thumbnails nos quais composições possíveis foram visualizadas. Esses esboços foram desenvolvidos e alterados durante o processo de desenho devido ao pensamento em ação proposto por SCHÖN (2016). Geralmente, esse era um processo bastante interno, no qual imagens de referência não eram usadas; em vez disso, os potenciais que surgiram no processo foram respondidos, entrando em um auto diálogo e tornando o pensamento explícito.

\section{Moodboarding}

Moodboarding ${ }^{3}$ foi usado como um método para refletir sobre composições criadas por outros profissionais (Figura 1). De particular influência nesta fase foi o trabalho de pintores holandeses como Rembrandt e Vermeer; na maneira pela qual a luz (e sua ausência) constrói forma e ênfase em composições complexas.

Os quadros de humor permitiram que diferentes abordagens de iluminação fossem comparadas e comunicadas com o assistente de iluminação durante a gravação. Assim, os mood boards tornaramse tanto instrumentos para o planejamento de composições quanto fontes de discussão no trabalho colaborativo.
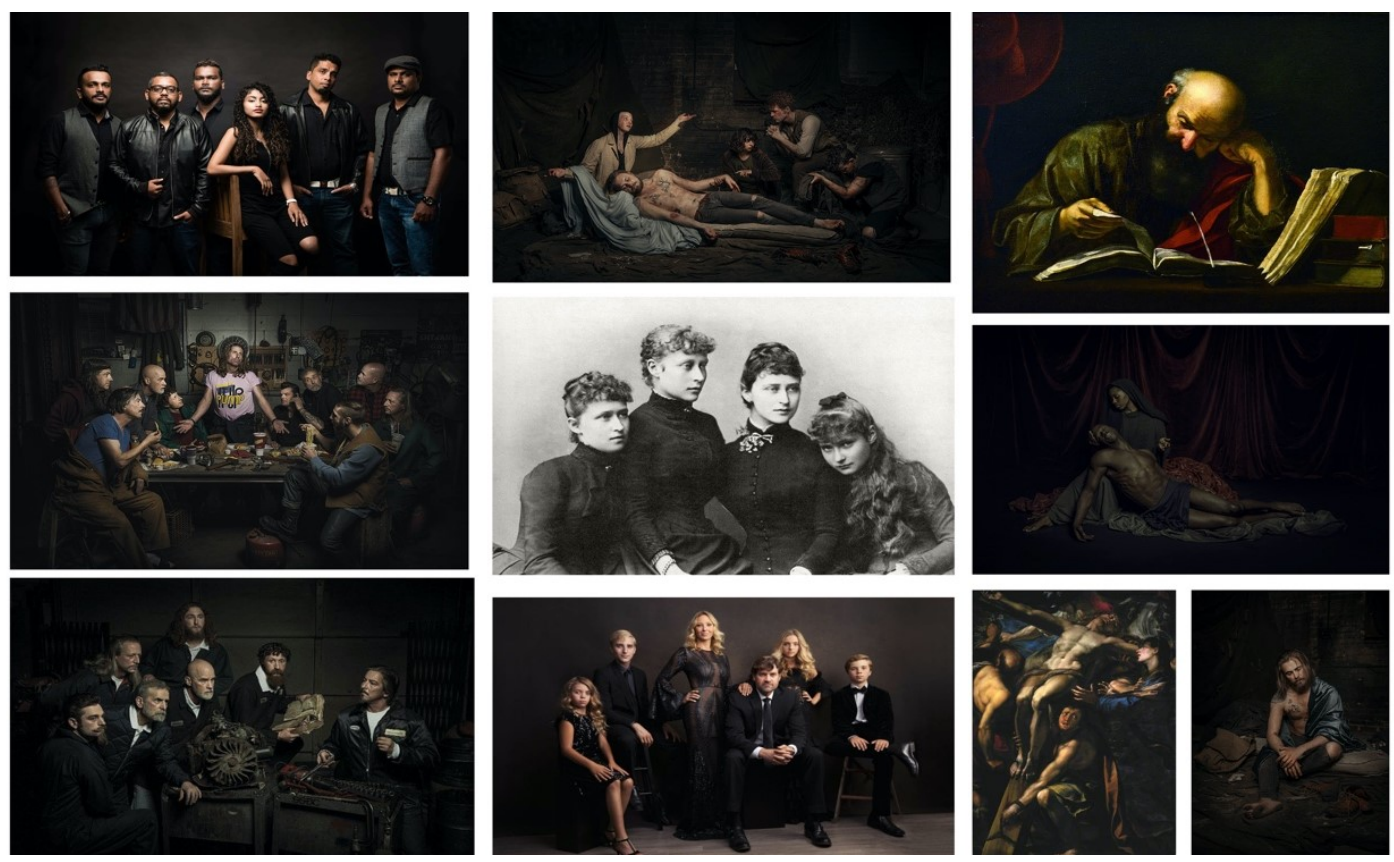

Figura 1: Um painel semântico para uma sessão fotográfica em estúdio em fevereiro de 2020, considerando questões de luz e composição de grupo.

\footnotetext{
${ }^{3}$ Um moodboard é uma coleção de imagens, texturas ou textos que são reunidos em uma página quando alguém está considerando uma ideia específica. O conjunto cria um composto de material visual que pode ser usado para refletir sobre ideias ou comunicá-las a outras pessoas. Este método foi usado para visualizar abordagens potenciais ao uso de cor, composição e luz.
} 


\section{Registro reflexivo}

A reflexão permeou todas as fases da pesquisa. Embora as produções envolveram um processo de planejamento colaborativo, trabalho com modelos e pós-produção, também foi empregado um registro reflexivo que ajudou a externar e refletir sobre o que foi descoberto. Foi um registro de ideias, experimentos e perguntas. Este diário ou jornal integrou elementos do "verdadeiro drama interno da pesquisa, com sua base intuitiva, sua linha do tempo hesitante e sua extensa reciclagem de conceitos e perspectivas" (MARSHALL \& ROSSMAN, 1995, p. 2).

Os benefícios do registro reflexivo foram três. Em primeiro lugar, permitiu as ideias serem registradas à medida que surgissem, servindo como uma fonte tanto para o planejamento das filmagens quanto para a escrita. Dado que a reflexão ocorreu dentro do processo de realização do trabalho, as notas gravadas permitiram o registro de pensamentos e, posteriormente, traçadas conexões entre eles. Tal reflexão na prática BOLTON (2010, p. xix) descreve como "prestando atenção crítica aos valores práticos e teorias que informam as ações cotidianas, examinando a prática reflexiva e de modo reflexivo. Isso leva a uma visão do desenvolvimento". Assim, o diário tornou-se um documento sintetizador no qual o pensamento pode ser refletido por meio de um processo de autodiálogo escrito. Em segundo lugar, o registro agia como um indicador de qual conhecimento contextual exigia discussão na escrita exegética. Finalmente, o registro reflexivo foi útil ao planejar experimentos futuros porque forneceu um mapa da trajetória e uma lista de referência específica, principalmente ao planejar a sessão em estúdio fotográfico.

\section{Estágio 2: Execução}

\section{Registro em estúdio}

Grande parte do estudo ocorreu nos estúdios de fotografia da Auckland University of Technology. Uma câmera digital SLR (single lens reflex) foi usada para registrar as fotografias e as imagens em movimento, em razão de esse dispositivo permitir ao usuário alternar facilmente entre a gravação de fotos e vídeo. Em testes posteriores, apenas a função de gravação de vídeo da câmera foi usada porque usar uma captura de quadro das imagens gravadas mostrou-se mais eficaz. Devido à natureza da câmera digital, é possível visualizar as imagens enquanto eram gravadas e ajustar a composição com base no que foi visto na tela.

\section{Testes de iluminação}

A fotografia é um meio que registra o reflexo da luz em um sensor digital e, portanto, a luz foi fundamental na criação dessas imagens. As primeiras investigações testaram os potenciais de configurações de iluminação natural e artificial (Figura 2). No entanto, após vários experimentos, percebeu-se que, uma vez que a gravação de filmes estava sendo usada para criar imagens, os aparelhos de iluminação tradicionais para retratos não funcionariam. Consequentemente, experimentaram-se esquemas de iluminação em estúdio. Os sistemas de iluminação contínua foram projetados para uso específico com vídeos, integrando sistemas de flash iluminados por lâmpadas piloto. Esta abordagem permitiu um maior nível de controle sobre a intensidade da luz e a direção a ser exercida. 


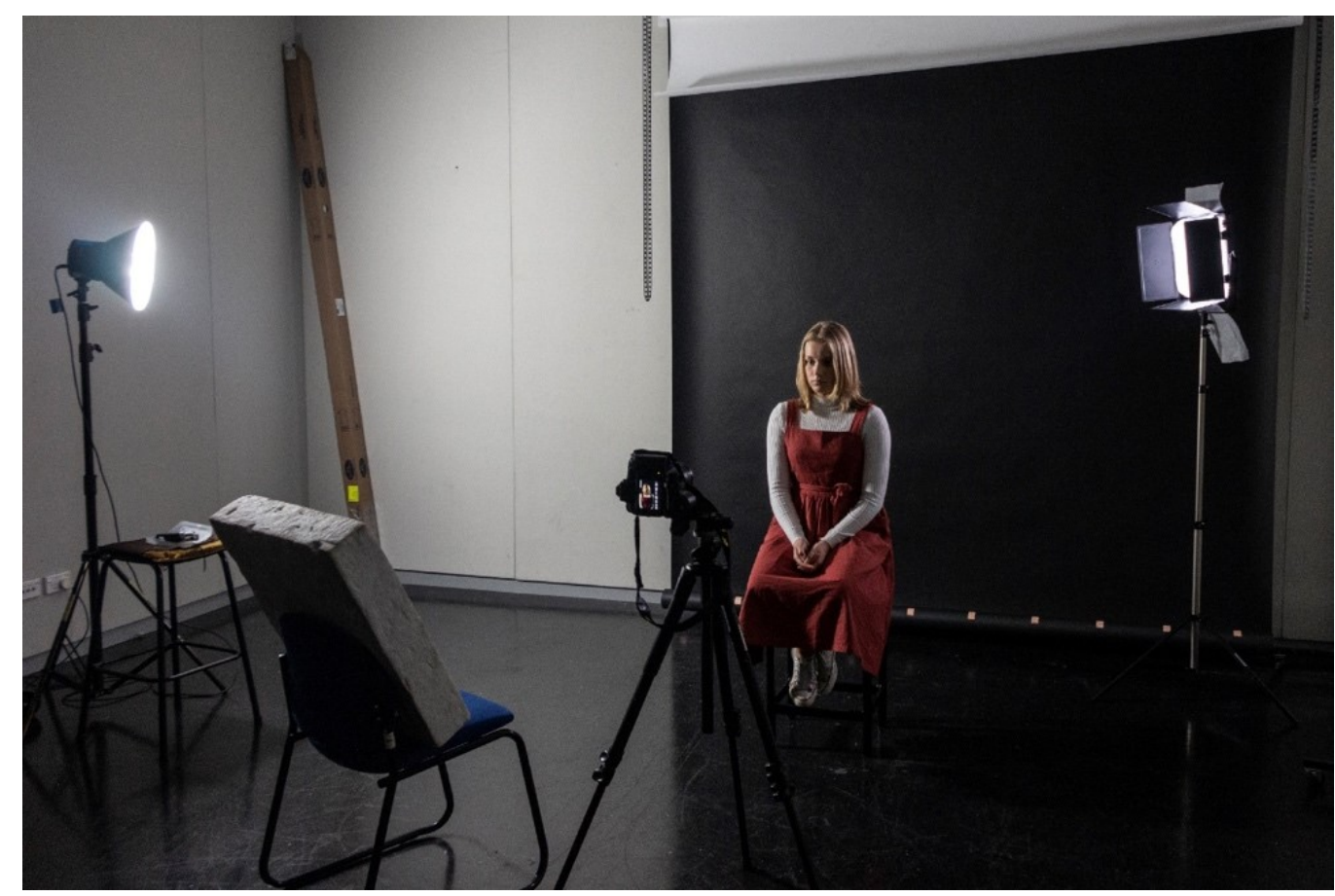

Figura 2. Configurações de iluminação na primeira sessão de fotos do projeto. A primeira filmagem usou iluminação de vídeo. No entanto, após testar as luzes do sistema de flash na segunda foto, descobriu-se que a iluminação era muito mais suave no tema. Essa iluminação mais suave combinada com o fundo muito mais escuro resultou na decisão de prosseguir com a investigação em um espaço de estúdio que oferecesse mais flexibilidade com o design de iluminação.

Embora inicialmente se buscasse iluminação para retratos dramáticos, o espaço também era necessário para o movimento dos objetos. A natureza de um durégraph é mover-se além de um único momento "congelado" no qual a luz e a composição são reproduzidas como gravações estáticas. Por causa das transições de movimento dentro desses retratos, a maneira pela qual a luz transitou conforme a forma evoluída do retrato também precisava ser considerada. Um projeto de iluminação focado somente para a composição normalmente não funcionaria porque o modelo se moveria dentro do quadro compositivo.

\section{Colaboração}

Durante o processo de gravação em estúdio, foi útil buscar uma rede de especialistas. Essa abordagem permitiu que recursos fossem localizados para os brotos, informações técnicas ou conselhos de desempenho fossem utilizados e o custo financeiro da pesquisa fosse reduzido. Gray (1996, p. 12) define colaboração como um processo de "apoio prático, crítica, encorajamento no qual as ideias estão abertas para troca e compartilhamento". Essa definição difere do termo "cooperação" dentro em ROSCHELLE e TEASLEY $(1995$, p. 70$)$, que remete a um processo no qual se orquestra uma "divisão de trabalho entre os participantes [...] no qual cada pessoa é responsável por uma parte da resolução do problema". Em um processo colaborativo, os potenciais inerentes ao pensamento de outras pessoas permaneceram abertos.

O processo colaborativo é importante em uma sessão de estúdio porque, como diretor e fotógrafo, era fundamental permanecer o mais focado possível no ethos da gravação. Estar "reflexivamente dentro" da evolução do que foi visto foi fundamental o sucesso da operação. 
Após discussões com outros fotógrafos e diretores de cinema, entendeu-se que o potencial de importar conhecimentos complementares em áreas como iluminação, figurino e produção seria benéfico. Um exemplo disso foi o apoio que recebi de um especialista em fantasias que não apenas me ajudou a encontrar o material, mas também me explicou como os figurinos devem ser administrados durante uma filmagem.

Ao empregar níveis significativos de colaboração, não só as questões artísticas atuais em questão poderiam ser focalizadas, mas também conselhos ou opiniões de especialistas que estavam temporariamente incorporados à pesquisa. $\mathrm{O}$ emprego desses níveis resultou na capacidade de permanecer "aberto à descoberta de fenômenos, incongruentes com a definição inicial do problema, com base na qual [...] o problema [é reenquadrado]" (SCHÖN, 2016, p. 268).

Neste projeto, atores profissionais foram contratados em vez de modelos, porque eles estavam mais familiarizados com a execução de emoções de "transição" para a câmera. Em outras palavras, eles foram capazes de mudar de um estado emocional para outro durante uma tomada contínua. Embora inicialmente os atores fossem dirigidos com base nas aparências a serem gravadas, entendeu-se que, para obter melhores resultados, a "intenção" de uma filmagem deveria ser discutida com eles. Eles queriam trabalhar por motivação. Consequentemente, as sessões começaram a ser construídas para produzir narrativas com elevados níveis de originalidade e autenticidade.

\section{Estágio 3: O Estúdio Digital}

\section{Edição e manipulação}

Uma vez que os dados visuais foram registrados, eles progrediram iterativamente através de uma série de experimentos guiados pela ideia da observação de SCHÖN (2016, p. 275) de que, durante esses espaços de tempo, "tende a mudar em períodos de tempo mais longos do que um único episódio de prática, embora eventos particulares possam acionar sua mudança. E às vezes são alterados por meio da reflexão do praticante sobre os eventos de sua atividade". Durante a edição e manipulação de imagens, seu potencial continuou a ser refletido. Como uma gama de variações de cada cenário foi reunida, foi possível mover-se entre eles, avaliando e questionando potenciais ênfases e nuances.

Frequentemente, a edição de imagens criava resultados variados a partir da mesma filmagem. A descoberta e a experimentação com o tempo e o movimento dos elementos dentro da moldura foram enriquecedoras nesta fase da pesquisa. Como o trabalho foi navegado heuristicamente, afastar-se de influências externas foi uma ocorrência frequente durante esta fase da pesquisa, tornando-se corporificado no que estava sendo criado e sentindo o caminho a seguir ao questionar o que estava surgindo tanto externa quanto internamente. É útil lembrar aqui a nota de DOUGLASS e MOUSTAKAS (1985, p. 63), “em sua forma mais pura, heurística é um envolvimento pessoal apaixonado e criterioso na resolução de problemas, um esforço para saber [...] por meio dos caminhos internos do self'"

\section{Estágio 4: Crítica especializada}

A fase final não foi isolada das três que a precederam. $\mathrm{O}$ feedback foi buscado nas Fases 1 e 2 e nos experimentos finais da Fase 3. Ao se engajar em discussões críticas com especialistas, tanto a clareza da comunicação quanto a profundidade da reflexão no trabalho puderam melhorar. No processo de investigação foram consultados o Dr. Marcos Steagall (fotógrafo), o Professor Welby Ings (cineasta) 
e Gregory Bennet (artista digital). Normalmente, o feedback profissional está relacionado a uma ideia específica de preocupação. No entanto, as visualizações do trabalho em andamento também foram configuradas para que questões técnicas ou conceituais específicas pudessem ser discutidas. Como MORTENSEN STEAGALL (2018, 2019, 2020), VENTLING (2018) e INGS (2011) sugerem, em uma investigação heurística, é necessário manter um nível de discrição em torno do feedback e consideração cuidadosa para aceitar ou rejeitar críticas ou conselhos imediatamente. As discussões críticas ajudaram a traçar correlações entre a prática e o refinamento conceitual, e a estender a amplitude e a profundidade das considerações técnicas, estéticas e teóricas na pesquisa.

\section{A OBRA CRIATIVA}

Esta seção apresenta uma amostra da obra de arte desenvolvida ao longo desta pesquisa conduzida pela prática, com um comentário sobre a prática que pretende oferecer uma visão interna dos formadores da base contextual do artefato.

\section{Champanhe e lágrimas}

Este trabalho (Figuras 3 e 4) explorou as relações entre antecipação e descontinuidade. De todos os retratos, "Champanhe e lágrimas" é o mais obviamente perturbador das experiências racionais de tempo e movimento. A mulher está vestida de preto, então nossa atenção é atraída para a relação entre seu rosto e a taça. Inicialmente, seus olhos estão baixos.

A parte mais focada da imagem é a taça de champanhe e está posicionada no primeiro terço do quadro. Este vidro é um acento que forma uma extremidade de uma estrutura composicional baseada no contraste. Aqui a forma é dividida em detalhes acesos e apagados que constituem triângulos conjuntos na forma de um "W". Este recurso é usado para enfatizar tanto a alienação quanto o ritmo no trabalho: A taça está paradoxalmente conectada à modelo e alienada em relação à modelo. 

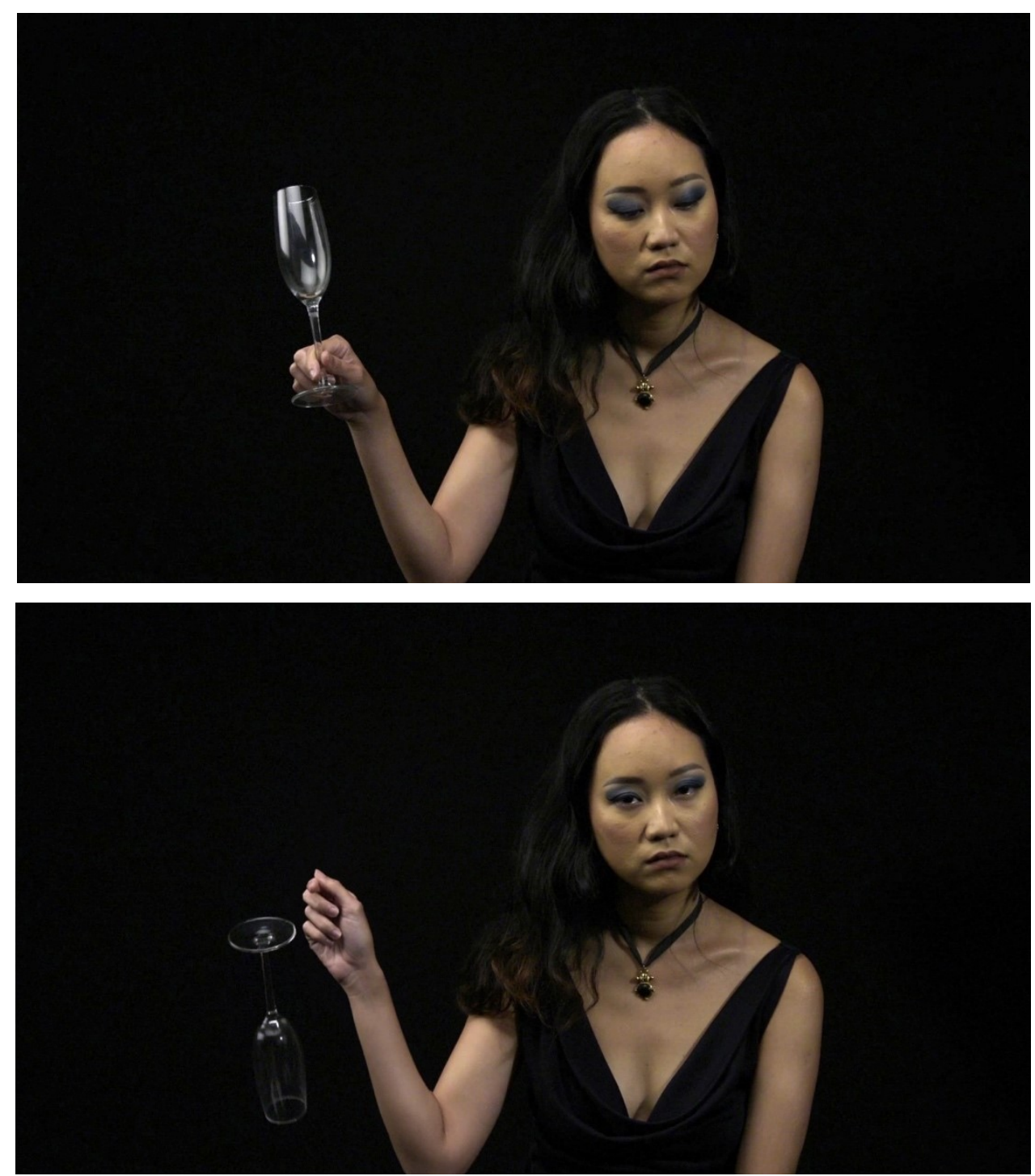

Figura 3 e 4. Imagens capturadas de Champagne Tears. C David van Vliet (2020).

\section{Emoção e movimento}

Enquanto a durégraph é exibido, observamos enquanto a mulher permite que sua taça tombe de suas mãos e começa uma descida temporária antes de congelar enigmaticamente no ar. Isso é tanto uma interrupção da quietude quanto um desafio à antecipação. Leis racionais de tempo e movimento estão suspensas no terço esquerdo do quadro. Após a ruptura, o conhecimento do modelo se revela na segunda e terceira seções, de maneira lenta, mas inteiramente lógica. Ela ergue os olhos e afasta a mão do vidro suspenso. Enquanto ela nos observa, quase de forma acusadora, seus olhos se enchem de lágrimas inexplicáveis, gerando mistério e conflito. $\mathrm{O}$ brilho de suas lágrimas emergindo lentamente está exatamente no mesmo nível de contraste que a luz na taça suspensa. Esta característica do retrato é projetada para sugerir uma correlação enigmática.

\section{Punctum}

Em relação ao pensamento de BARTHES (1977), a detecção de conteúdo e movimento (studium) neste retrato progride para algo que nos punge com uma sensação de inquietação. Barthes descreve como punctum a resposta intensamente subjetiva que temos a uma imagem e não quantificável pelos detalhes que vemos. Em vez disso, punctum é algo que sentimos. 
Embora BARTHES (1981, p. 79) descreva uma fotografia como uma "imagem viva de uma coisa morta", uma durégraph não pode fazer essa afirmação porque a imagem sugere "vivacidade" em sua interrupção do tempo congelado. No entanto, pode-se argumentar que em uma durégraph ainda se pode vivenciar o punctum, como um efeito sensorial, intensamente subjetivo exercido pela imagem sobre o observador. BARTHES (1981, p. 27) diz: "O punctum de uma fotografia é aquele acidente que me punge (mas também me machuca, é comovente para mim)". Ao contrário de uma fotografia, o ponto em um durégraph pode se desenrolar através das mudanças no tempo e no movimento da mesma imagem, mas ainda pode produzir ou transmitir um significado único para o observador individual da imagem. O punctum em "Champanhe e lágrimas" pontua o estúdio e a tensão emocional na obra perfura o espectador. A experiência de punctum não é absoluta. Nem todos os espectadores sentirão as mesmas coisas sobre esta imagem (eles não serão perfurados da mesma forma). Isso porque Barthes sugere que o punctum não é a soma dos conteúdos do retrato fotográfico, mas, sim, algo surgido de detalhes além da intenção ou controle do fotógrafo.

\section{CRÍTICA DA METODOLOGIA}

A investigação heurística como uma abordagem metodológica para a pesquisa artística é baseada em altos níveis de questionamento crítico: um se baseia na autorreflexão astuta apoiada por crítica e aconselhamento externo estratégico. Essa abordagem oferece potenciais e desafios descritos a seguir.

\section{Potencial}

A ênfase na descoberta por meio do questionamento em uma investigação heurística muitas vezes levou a questões enriquecedoras, convivendo com elas por um longo tempo; e permitindo que as descobertas eventualmente se manifestem através da prática. Essa valorização de questionar sem uma solução imediata e visualizada muitas vezes se abriu para um pensamento mais rico porque aumentou a quantidade de tempo na qual uma ideia era vivida.

A investigação heurística também proporcionou níveis comparativamente altos de flexibilidade porque não se baseia em uma fórmula ou modelo predeterminado para a realização de pesquisas. Isso significa que altos níveis de capacidade de resposta ao que foi encontrado podem ser mantidos, e a pesquisa deve se mover em direções não previstas no início do projeto.

\section{Desafios}

No entanto, a investigação heurística também apresentou uma série de desafios. Devido à natureza da presença na prática, havia um risco significativo de que as perguntas não levassem à criação de trabalho, mas resultassem, em vez disso, em mais perguntas. Para remediar esses desafios, a pergunta sempre foi respondida com prática. $\mathrm{O}$ uso da prática para conduzir a investigação manteve $\mathrm{o}$ pensamento fundamentado na questão central que orienta a tese: como um retrato produzido na interseção da fotografia e da imagem em movimento pode ser usado para desafiar as expectativas sobre o tempo, a antecipação, o imediatismo e o significado?

Abrir o projeto à crítica externa também representava um risco significativo. Era importante permitir feedback apenas nos pontos em que as questões atingiram um ponto de resolução adequado. Devido à natureza profundamente pessoal da investigação heurística, o pensamento no projeto pode se tornar muito vulnerável a dúvidas. Isso pode ser porque, na investigação heurística, ao contrário de muitas outras abordagens metodológicas, não existe uma fórmula definida contra a qual se possa justificar suas ações. Muitas vezes, descobriu-se que as ideias que "pareciam" certas não podiam ser defendidas. Para resolver esta situação, o pensamento gestacional foi muitas vezes "protegido" 
enquanto a ideia era feita. Somente depois que tomou forma, o feedback foi solicitado. Isso porque, uma vez que uma ideia era física, ela podia ser externalizada e considerada de forma mais objetiva.

Finalmente, em uma investigação heurística, um projeto pode se tornar muito exigente em termos de tempo e recursos. Ao criar redes com outros pesquisadores e profissionais, decisões estratégicas podem ser feitas sobre modelos, figurinos e maquiagem. As implicações financeiras também foram consideradas no início de cada filmagem, para que os limitados recursos de pesquisa pudessem ser distribuídos estrategicamente ao longo da trajetória do estudo.

\section{CONCLUSÃO}

Este artigo demonstrou a abordagem metodológica desenvolvida para criar as durégraphs apresentados no endereço url https://www.duregraph.com. Como uma pesquisa conduzida pela prática, o projeto de pesquisa considerou como a duração pode ser articulada por meio do retrato fotográfico e quais implicações e efeitos isso pode ter sobre o papel do espectador.

Todos os estudos fotográficos da coleção usam a duração como meio de expandir o modo pelo qual pode encontrar um retrato. Cada imagem representa o tempo de maneira diferente, mas todas ativam e restringem o movimento de forma intermitente. Ao fazer isso, elas desafiam a forma como vemos o tema (ou temas)em um retrato. Ao visualizar essas imagens, experimenta-se uma "espera proveitosa" em um ambiente onde tal espera pode produzir valor e sentido.

\section{REFERÊNCIAS}

BARTHES, R. Imagem, Música e Texto. Fontana Press, 1977.

BARTHES, R. Camera Lucida: Reflections on Photography. Farrar, Straus and Giroux, 1981.

BOLTON, G. (2010). Reflective practice: writing and professional development. Sage, 2010.

CANDY, L. Practice Based Research: A Guide. C. C. Studios, CCS Report: 2006-V1.0 November 2006.

DOUGLASS, B. G., \& MOUSTAKAS, C. Heuristic Inquiry: The Internal Search to Know. Journal of Humanistic Psychology, 25(3), 39-55, 1985. https://doi.org/10.1177/0022167885253004

GRAY, C. (1996). Inquiry through practice: Developing appropriate research strategies No Guru, No Method? International Conference on Art and Design Research, Helsinki, Finland, 1996. http://carolegray.net/Papers\%20PDFs/ngnm.pdf

GUBA, E. G., \& Lincoln, Y. S. Competing Paradigms in Qualitative Research. In N. K. Denzin \& Y. S. Lincoln (Eds.), Handbook of qualitative research (pp. 105-117). Sage, 1994.

INGS, W. Managing Heuristics as a Method of Inquiry in Autobiographical Graphic Design Theses. International Journal of Art \& Design Education, 30(2), 72-87, 2011. https://doi.org/10.1111/j.1476-8070.2011.01699.x

KLEIN, J. What is Artistic Research? Gegenworte, 23, 2010. https://media.researchcatalogue.net/rc/master/57/85/bf/29/5785bf295ddfff55902b08051f9c1143.pdf $? \mathrm{t}=036 \mathrm{efe} 4 \mathrm{~b} 4 \mathrm{ca}$ 6ac7a8ab842c1f60c955e\&e $=1580977500$

MACKENZIE, N., \& KNIPE, S. Research dilemmas: Paradigms, methods and methodology. Educational Researcher, 16(2), 193-205, 2006.

MARSHAL, C., \& ROSSMAN, G. B. Designing Qualitative Research. Sage Publications, 1995 
MATHIJSSEN. Composition, 2010. https://isb-visualarts.weebly.com/composition.html

MORTENSEN STEAGALL, Marcos; INGS, Welby. Pesquisa de doutorado practice-led e a natureza dos métodos imersivos. DAT Journal, 2018, vol. 3, no 2, p. 392-423.

MORTENSEN STEAGALL, Marcos. The Process of Immersive Photography: Beyond the Cognitive and the Physical, (Doctoral dissertation, Auckland University of Technology), 2019.

MORTENSEN STEAGALL, Marcos. Imagens conceituais na publicidade: premissas da imagem publicitária potenciadas pela tecnologia e interavidade. Convergências: Revista de Investigação e Ensino das Artes., 2020, vol. 13, p. 1-6.

MOUSTAKAS, C. E. Heuristic research: design, methodology, and applications [Electronic $\begin{array}{llll}\text { document]. } & \text { Sage } & \text { Publications, }\end{array}$ http://ezproxy.aut.ac.nz/login?url=http://methods.sagepub.com/book/heuristic-research-designmethodology-and-applications

PALLASMAA, J. Embodied and Existential Wisdom in Architecture: The Thinking Hand [Article]. Body and Society, 23(1), 96-111, 2017. https://doi.org/10.1177/1357034X16681443

ROSHELLE, J., \& TEASLEY, S. D. The Construction of shared knowledge in collaborative problem solving. In C. O'Malley (Ed.), Computer-supported collaborative learning (pp. 69-97). Springer, 1995.

RUST, C., MOTTRAM, J., \& TILL, J. Review of practice-led research in art, design \& architecture. Arts and Humanities Research Council, 2007.

SARANTAKOS, S. Social Research. Macmillan Education Australia, 1993.

SARTRE, J.-P. Being and Nothingness (H. E. Barnes, Trans.). Philosophical Library, 1956.

SCHÖN, D. A. The reflective practitioner: how professionals think in action. Routledge, 2016. http://ebookcentral.proquest.com/lib/aut/detail.action?docID $=4816972$.

SELA-SMITH, S. Heuristic Research: A Review and Critique of Moustakas's Method. Journal of $\begin{array}{llll}\text { Humanistic Psychology, } & \text { 42(3), } & \text { 53-88, }\end{array}$ https://doi.org/https://doi.org/10.1177/0022167802423004

VENTLING, F. D. Heuristics - A framework to clarify practice-led research. Journal of Design, Art \& Technology [DAT], 3(2), 122-157, 2018. 